RESEARCH REPORT

\title{
Trends in smoking behaviour between 1985 and 2000 in nine European countries by education
}

\author{
K Giskes, A E Kunst, J Benach, C Borrell, G Costa, E Dahl, J A A Dalstra, B Federico, U Helmert, \\ K Judge, E Lahelma, K Moussa, P O Ostergren, S Platt, R Prattala, N K Rasmussen, J P Mackenbach
}

J Epidemiol Community Health 2005;59:395-401. doi: 10.1136/jech.2004.025684

See end of article for authors' affiliations

Correspondence to:

Dr K Giskes, Department of Public Health, Erasmus Medical Centre, PO Box 1738, 3000DR Rotterdam, Netherlands; k.giskes@ erasmusmc.nl

Accepted for publication 30 November 2004

\begin{abstract}
Objective: To examine whether trends in smoking behaviour in Western Europe between 1985 and 2000 differed by education group.

Design: Data of smoking behaviour and education level were obtained from national cross sectional surveys conducted between 1985 and 2000 (a period characterised by intense tobacco control policies) and analysed for countries combined and each country separately. Annual trends in smoking prevalence and the quantity of cigarettes consumed by smokers were summarised for each education level. Education inequalities in smoking were examined at four time points.

Setting: Data were obtained from nine European countries: Norway, Sweden, Denmark, Finland, the United Kingdom, the Netherlands, Germany, Italy, and Spain.

Participants: 451386 non-institutionalised men and women 25-79 years old.

Main outcome measures: Smoking status, daily quantity of cigarettes consumed by smokers.

Results: Combined country analyses showed greater declines in smoking and tobacco consumption among tertiary educated men and women compared with their less educated counterparts. In country specific analyses, elementary educated British men and women, and elementary educated Italian men showed greater declines in smoking than their more educated counterparts. Among Swedish, Finnish, Danish, German, Italian, and Spanish women, greater declines were seen among more educated groups.

Conclusions: Widening education inequalities in smoking related diseases may be seen in several European countries in the future. More insight into effective strategies specifically targeting the smoking behaviour of low educated groups may be gained from examining the tobacco control policies of the UK and Italy over this period.
\end{abstract}


Table 1 Survey characteristics in participating countries

\begin{tabular}{|c|c|c|c|c|c|c|}
\hline \multirow[b]{2}{*}{ Country } & \multirow[b]{2}{*}{ Survey years } & \multirow[b]{2}{*}{ Survey name } & \multirow[b]{2}{*}{ Response rate } & \multirow{2}{*}{$\begin{array}{l}\text { Proportion with low } \\
\text { education (sex } \\
\text { combined) }\end{array}$} & \multicolumn{2}{|c|}{ Number of respondents $25-79$ years } \\
\hline & & & & & Men & Women \\
\hline \multirow[t]{4}{*}{ Norway } & 1985 & $\begin{array}{l}\text { Smoking prevalence and } \\
\text { social surveys }\end{array}$ & 58 & 31.9 & 990 & 996 \\
\hline & 1990 & & 58 & 25.6 & 1005 & 1051 \\
\hline & 1995 & & 58 & 20.6 & 600 & 584 \\
\hline & 2000 & & 58 & 15.9 & 584 & 634 \\
\hline \multirow[t]{4}{*}{ Sweden } & $1988-1989$ & $\begin{array}{l}\text { Swedish survey of living } \\
\text { conditions survey }\end{array}$ & 86 & 37.2 & 4987 & 5143 \\
\hline & $1992-1993$ & & 86 & 28.9 & 4916 & 4955 \\
\hline & $1996-1997$ & & 86 & 26.3 & 4668 & 4908 \\
\hline & 2000-2001 & & 85 & 21.8 & 4604 & 4886 \\
\hline \multirow[t]{4}{*}{ Finland } & 1986 & $\begin{array}{l}\text { Finnish health behaviour and } \\
\text { health survey }\end{array}$ & 82 & 48.1 & 1414 & 1670 \\
\hline & 1991 & & 82 & 36.6 & 1380 & 1576 \\
\hline & 1996 & & 72 & 28.7 & 1330 & 1525 \\
\hline & 2001 & & 70 & 22.0 & 1272 & 1467 \\
\hline \multirow[t]{3}{*}{ Denmark } & 1987 & $\begin{array}{l}\text { Danish health and morbidity } \\
\text { survey }\end{array}$ & 80 & 36.0 & 1820 & 1875 \\
\hline & 1994 & & 78 & 25.1 & 1798 & 1956 \\
\hline & 2000 & & 74 & 19.2 & 6783 & 6958 \\
\hline \multirow[t]{4}{*}{ United Kingdom } & 1984 & General household survey & 83 & 53.6 & 6764 & 7850 \\
\hline & 1990-1991 & & 83 & 45.0 & 6700 & 7612 \\
\hline & $1994-1995$ & & 82 & 38.9 & 6430 & 7551 \\
\hline & $2000-2001$ & & 68 & 27.7 & 6019 & 6558 \\
\hline \multirow[t]{3}{*}{ Netherlands } & 1990 & National health survey & 56 & 22.8 & 2405 & 2506 \\
\hline & 1995 & & 59 & 22.8 & 3102 & 3250 \\
\hline & 1999 & & 56 & 18.7 & 3067 & 3237 \\
\hline \multirow[t]{4}{*}{ Germany† } & 1984 & $\begin{array}{l}\text { German national health } \\
\text { survey }\end{array}$ & 66 & 66.7 & 2417 & 2373 \\
\hline & 1987 & & 71 & 64.4 & 2620 & 2644 \\
\hline & 1990 & & 69 & 60.2 & 2590 & 2665 \\
\hline & 1998 & & 61 & 51.2 & 1724 & 1840 \\
\hline \multirow[t]{4}{*}{ Italy } & 1986-1987 & $\begin{array}{l}\text { Population health conditions } \\
\text { and use of healthcare services } \\
\text { survey }\end{array}$ & 92 & 52.0 & 23591 & 25152 \\
\hline & 1990-1991 & & 89 & 44.4 & 21335 & 22560 \\
\hline & 1994 & & 86 & 39.2 & 19917 & 21323 \\
\hline & 1999-2000 & & 87 & 35.9 & 47221 & 50498 \\
\hline \multirow[t]{4}{*}{ Spain } & 1987 & Continuing health survey & 90 & 39.8 & 10855 & 12032 \\
\hline & 1993 & & 90 & 17.8 & 7775 & 8411 \\
\hline & 1995 & & 85 & 16.2 & 2352 & 2602 \\
\hline & 1997 & & 85 & 8.0 & 2373 & 2603 \\
\hline
\end{tabular}

was available for men and women, regardless of whether they were in the workforce. It is comparable between countries (where income is less so) and it is a comparatively stable socioeconomic indicator over time, as it does not change to a large degree among adults over 25 years of age. Additionally, it was the only SEP indicator that was measured in each country in the study. Education levels were re-grouped into a comparative classification for the combined country analyses, consisting of four categories: elementary (no education completed, elementary school only), lower secondary (intermediate high school, intermediate vocational education), higher secondary (higher levels of secondary school, higher vocational education), and tertiary (post-secondary education). In country specific analyses, these four categories were collapsed into two: the low education group consisted of participants with elementary level education and all higher levels were re-grouped in the high category. Table 1 provides details of the proportions in the low education category.

\section{Analyses}

Analyses were performed for all countries combined, and for each country separately. All analyses were stratified by sex. In the combined country analyses, the data from each survey within each country were pooled into four survey periods to calculate inequalities at given points in time. These time points were 1985, 1990, 1995, and 2000. Denmark and the
Netherlands were excluded from the combined country analyses, as data from these countries were only available for three time points. Weights were calculated and applied to the data in all combined country analyses, so that each country had equal representation. Combined country analyses were also adjusted for country to take into account the fact that the education distributions and smoking prevalence differed between countries. Participants with incomplete or missing data on smoking behaviour or education, or both, $(\mathrm{n}=15753,3.5 \%)$ were excluded from all analyses. Those identified as non-smokers were excluded from analyses of the quantity of cigarettes consumed. Participants from Sweden were also excluded from analyses of the quantity of cigarettes consumed, as these data were not collected in Sweden.

Annual trends were determined by entering education level, age, and the year of survey as independent variables into the logistic regression and general linear models (linear least squares regression models), with smoking status and quantity of cigarettes consumed as dependent variables, respectively. The regression coefficient and standard error of the year of survey term were used to calculate the slope estimate. The slope estimate was considered statistically significant if the 95\% confidence interval surrounding it excluded zero. An interaction term was entered into these models and the type III sums of squares were used to evaluate whether trends differed by education group. 
Table 2 Combined country smoking inequalities and smoking by education level among several Western European countries between 1985 and 2000 (25-79 years of age)*

\begin{tabular}{|c|c|c|c|c|}
\hline \multirow{2}{*}{$\begin{array}{l}\text { Education } \\
\text { level }\end{array}$} & \multicolumn{4}{|c|}{ Age standardised prevalence of current smoking (\%) } \\
\hline & 1985 & 1990 & 1995 & 2000 \\
\hline \multicolumn{5}{|l|}{ Men } \\
\hline 1 (low) & 44.88 & 43.74 & 39.50 & 36.30 \\
\hline 2 & 40.40 & 38.88 & 35.22 & 35.94 \\
\hline 3 & 39.14 & 31.05 & 27.49 & 27.17 \\
\hline 4 (high) & 28.87 & 26.60 & 25.71 & 22.56 \\
\hline RII $(95 \% \mathrm{Cl})$ & 2.63 (2.34 to 2.95$)$ & $3.17(2.81$ to 3.56$)$ & 3.08 (2.67 to 3.55$)$ & $2.67(2.30$ to 3.11$)$ \\
\hline \multicolumn{5}{|l|}{ Women } \\
\hline 1 (low) & 25.94 & 29.82 & 29.63 & 31.49 \\
\hline 2 & 24.70 & 25.56 & 24.83 & 24.94 \\
\hline 3 & 22.74 & 21.55 & 21.89 & 21.04 \\
\hline 4 (high) & 18.83 & 18.62 & 17.67 & 16.61 \\
\hline RII $(95 \% \mathrm{Cl})$ & $1.53(1.33$ to 1.75$)$ & 2.21 (1.91 to 2.57 ) & 2.67 (2.26 to 3.14$)$ & $3.16(2.67$ to 3.75$)$ \\
\hline
\end{tabular}

In the combined country analyses, current smoking rates and quantity of cigarettes consumed were calculated for each education group. These rates were age adjusted according to the direct method, using the age distribution of the European population as the standard. All further analyses were adjusted for age, which was entered as a continuous covariate into the models. Differences in smoking prevalence or cigarette consumption between education groups were determined by the Tukey test.

The magnitude of education inequalities in smoking was measured by calculating the relative index of inequality (RII) (with 95\% confidence intervals). The RII was chosen as it takes into account differences in smoking between education groups separately, but also takes into consideration the changing education distribution of the population. This was an important factor, as there are pronounced changes in the education distribution of the population over time, with populations becoming more educated.

For calculation of the RII, the relative position of each education group in the population education hierarchy was determined, and this was entered into the models as the percentage of the population with a higher education level (a continuous variable). This continuous education variable was related to smoking status and quantity of cigarettes consumed using logistic regression and general linear models (linear least square regression), respectively. In the analyses summarising education inequalities in smoking prevalence, the RII can be interpreted as the odds ratio between participants with the lowest education compared with those at the highest end of the education distribution. In analyses of education differences in the quantity of cigarettes consumed, it is interpreted as the difference in the quantity of cigarettes consumed between education groups at the extreme ends of the education range. ${ }^{67}$ Differences in the RII between time points were determined by examining whether RIIs had overlapping confidence intervals. To observe time trends, the RIIs at 1985 were compared with those of subsequent time points.

All analyses were conducted using SPSS version 10.0.7 (Chicago, IL). Variables or interaction terms entered in the models described above that were significant at $\mathrm{p} \leqslant 0.05$ (two tailed) were considered to be significant.

\section{RESULTS}

\section{Trends in smoking: countries combined}

Table 2 shows that in the combined country analyses, smoking was most prevalent among elementary educated men and women at all time points. When countries were analysed separately (results not shown), smoking was most prevalent among low educated men and women. The only exceptions to this finding were among Italian and Spanish women, where smoking was most prevalent among the high educated. Table 2 also shows there were no linear trends or statistically significant changes in inequalities in smoking seen among men during the period. However, a significant increase in inequalities in smoking among women was evident between 1985 and 2000, as seen by non-overlapping confidence intervals between 1985 and subsequent time points.

Figure 1 shows there were statistically significant annual declines in smoking among men from all education levels (all

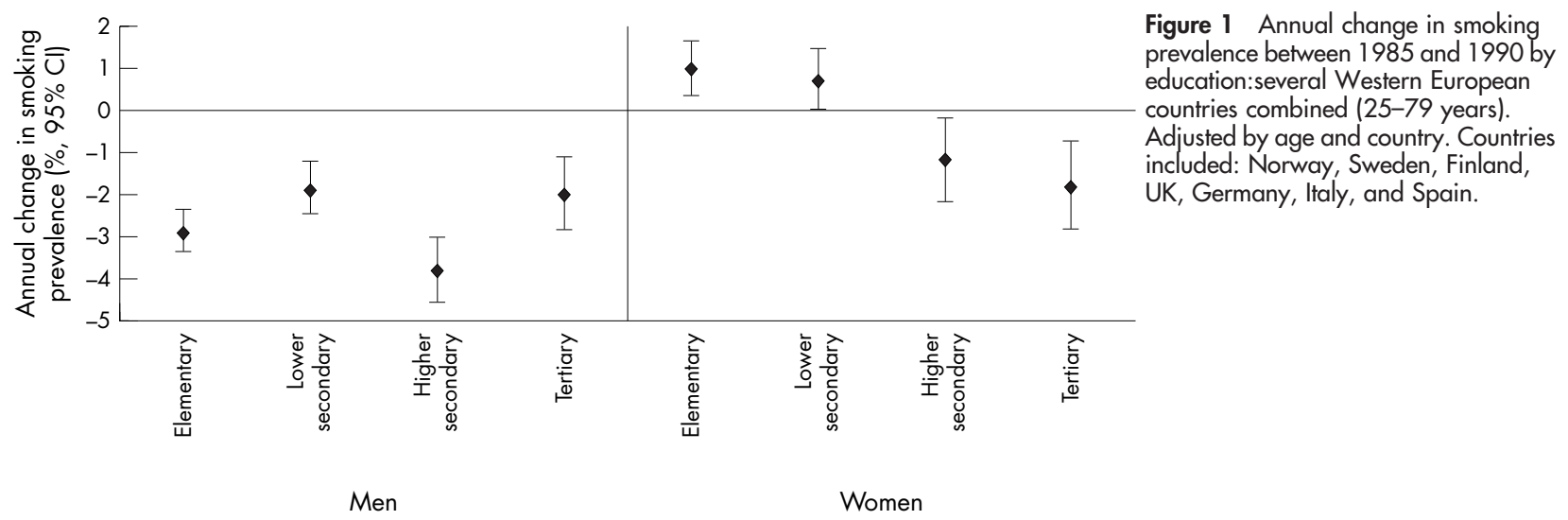

Figure 1 Annual change in smoking prevalence between 1985 and 1990 by education:several Western European

Adjusted by age and country. Countries included: Norway, Sweden, Finland, UK, Germany, Italy, and Spain.

Education level 


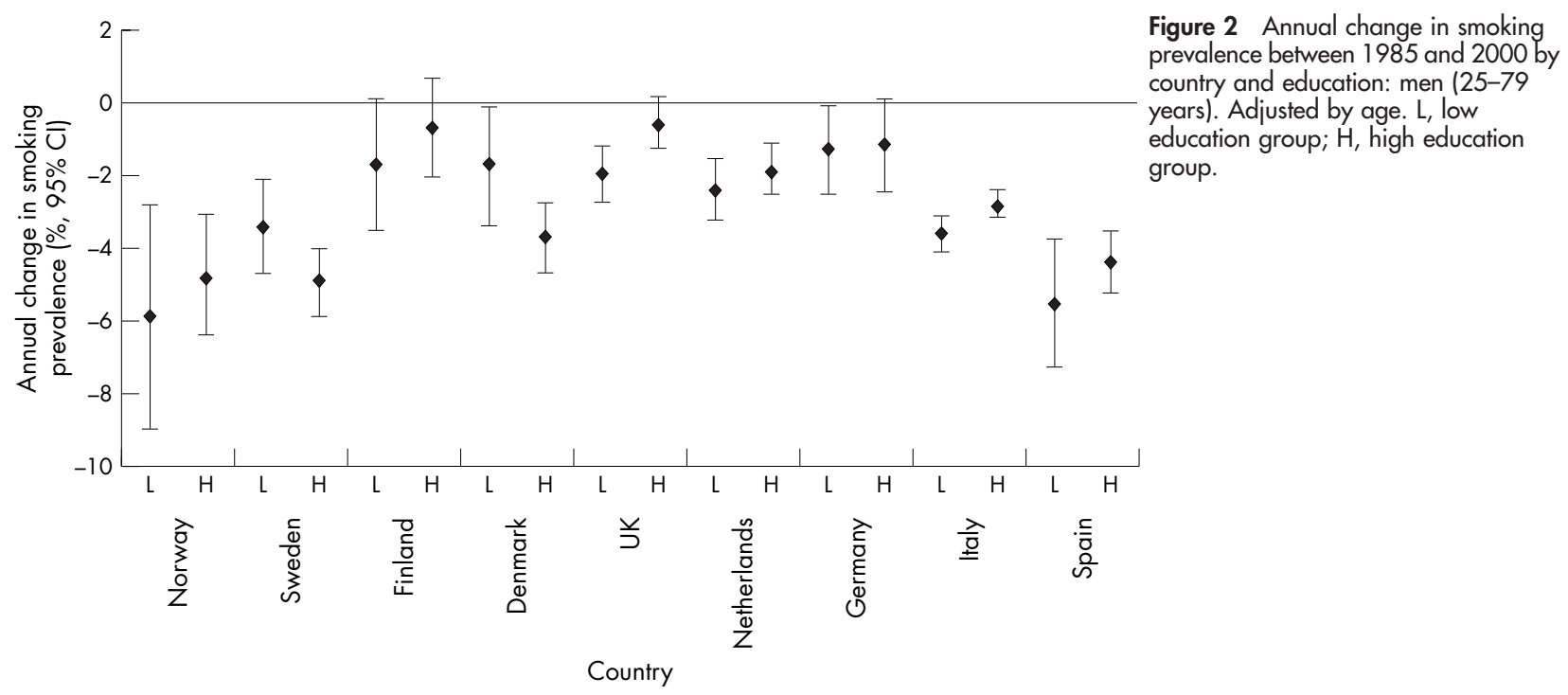

confidence intervals of the annual change estimates were less than 0 ). Men with a higher secondary education showed significantly larger declines than their lower secondary and tertiary educated counterparts ( $p$ value interaction $<0.01$ ). A linear effect of education level on annual change in smoking was evident among women ( $p$ value interaction $<0.01$ ), with the tertiary and higher secondary educated women illustrating significant declines. A significant increase in smoking was seen among elementary educated women, and the increasing trend in smoking prevalence seen among lower secondary educated women only reached borderline statistical significance (the lower bound of the confidence interval just reached zero).

\section{Trends in smoking: country specific}

Figures 2 and 3 show annual trends in smoking of each education groups and country for men and women, respectively. Figure 2 shows that less educated British and Italian men had greater declines in smoking than their more educated countrymen ( $\mathrm{p}$ value interaction $<0.01$ for both countries), however education differences in trends only reached borderline significance among Italian men ( $p$ value interaction 0.08). Greater declines in smoking among the less educated were also seen among Norwegian, Finnish, Dutch, and Spanish men, however they were not significantly different from those with more education. More educated Swedish and Danish men had slightly larger (although not different) declines in smoking compared with their less educated counterparts ( $p$ value interaction 0.27 and 0.15 for Swedish and Danish men, respectively).

Figure 3 shows that education differences in smoking trends were seen among women in almost all countries examined, but only reached significance among Swedish, Finnish, Danish, German, Italian, and Spanish women ( $p$ value interactions $<0.05$ for all countries). In these countries, more educated women showed the most favourable trends in smoking compared with the less educated group. A similar pattern was seen among Norwegian women, but differences between the education groups were not significant ( $p$ value interaction 0.37). Greater declines in smoking were evident among less educated British women compared with their more educated counterparts, this difference reached

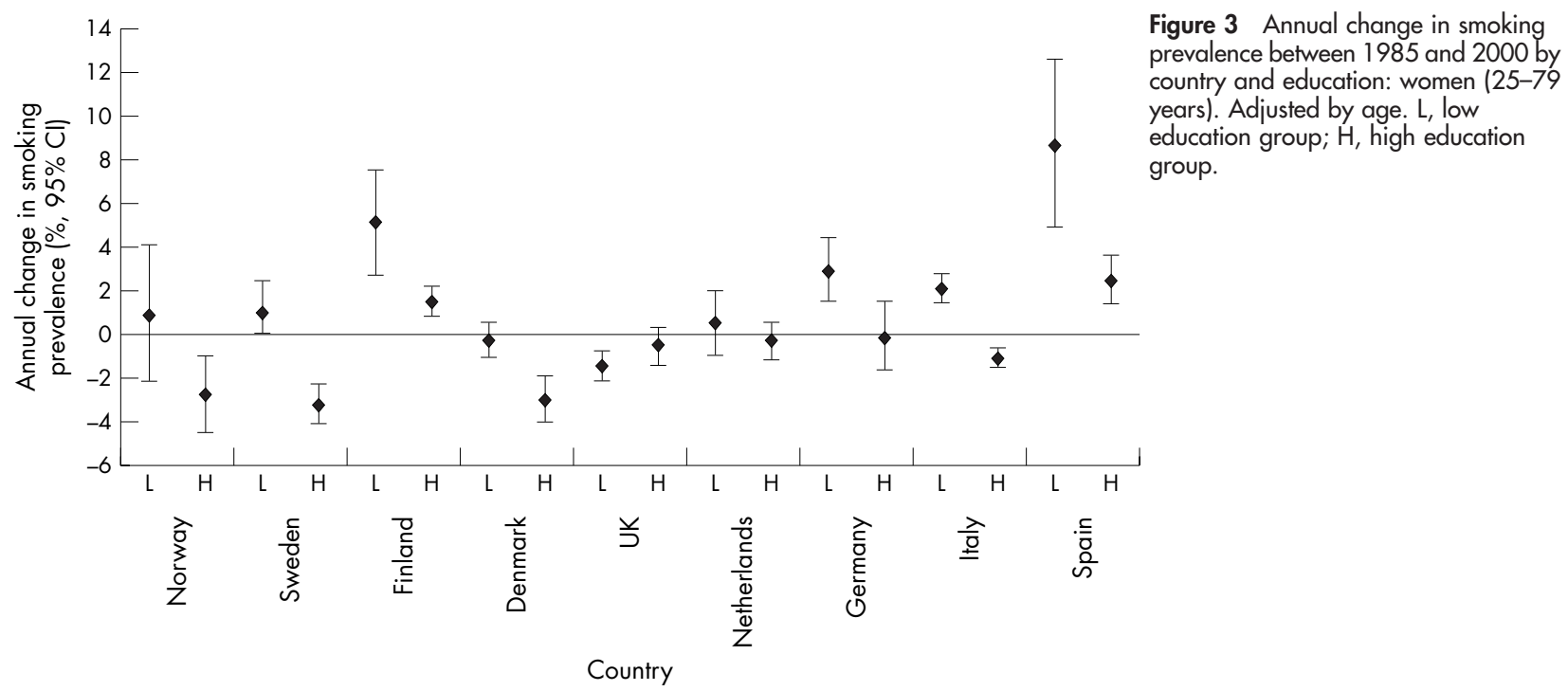




\begin{tabular}{|c|c|c|c|c|}
\hline \multirow[b]{2}{*}{ Education level } & \multicolumn{4}{|c|}{ Age standardised daily tobacco consumption (number of cigarettes or equivalent) } \\
\hline & 1985 & 1990 & 1995 & 2000 \\
\hline \multicolumn{5}{|l|}{ Men } \\
\hline 1 (low) & 14.88 & 15.33 & 15.49 & 15.50 \\
\hline 2 & 14.01 & 15.49 & 14.73 & 14.30 \\
\hline 3 & 14.15 & 14.88 & 14.15 & 13.60 \\
\hline 4 (high) & 14.43 & 14.01 & 13.74 & 12.55 \\
\hline $\operatorname{RII}(95 \% \mathrm{CI})$ & $1.48(1.35$ to 1.60$)$ & $1.27(1.16$ to 1.39$)$ & $1.43(1.32$ to 1.55$)$ & 1.57 (1.38 to 1.77$)$ \\
\hline \multicolumn{5}{|l|}{ Women } \\
\hline 1 (low) & 11.70 & 11.82 & 11.25 & 11.36 \\
\hline 2 & 9.49 & 11.59 & 11.82 & 11.24 \\
\hline 3 & 10.70 & 11.70 & 11.24 & 12.30 \\
\hline 4 (high) & 9.03 & 10.38 & 10.18 & 9.97 \\
\hline RII $(95 \% \mathrm{Cl})$ & 1.45 (1.28 to 1.65$)$ & $1.43(1.30$ to 1.57$)$ & $1.57(1.43$ to 1.70$)$ & 1.40 (1.26 to 1.57$)$ \\
\hline
\end{tabular}

borderline significance ( $\mathrm{p}$ value interaction 0.08). Among Dutch women, there was no difference in smoking trends evident between education groups ( $p$ value interaction 0.48 ).

\section{Quantity of cigarettes consumed by smokers}

Table 3 shows that education inequalities in the quantity of cigarettes consumed were significant at all time points for men and women, with tertiary educated smokers consuming less cigarettes in comparison with smokers from all other education groups ( $p$ values of all comparisons $<0.05$ ). The magnitude of inequalities in tobacco consumption did not change significantly among men and women over the time period examined (the confidence intervals around the RIIs overlapped at all time points).

Figure 4 shows graded education effects in annual changes in the quantity of cigarettes consumed among both men and women ( $p$ value interaction $<0.01$ for both men and women). Figure 4 shows that the quantity of cigarettes consumed by smokers increased annually among men and women with elementary and lower secondary education and among women with higher secondary education. Trends in tobacco consumption showed no statistically significant increasing or decreasing tendency among higher secondary educated men and tertiary educated women (confidence intervals of annual trends included the null). A statistically significant decline in the quantity of cigarettes consumed was seen among tertiary educated men (annual trend and confidence interval were below 0 ).

\section{DISCUSSION}

\section{Summary of findings}

The results of the combined country analyses showed that smoking declined less among low educated men and women compared with their more educated counterparts. Pronounced education differences in smoking prevalence trends were seen among Swedish, Finnish, Danish, German, Italian, and Spanish women. Reverse education differences (where declines were greatest among the low educated groups) were seen among British men and women, and among Italian men. The findings support the view that in the region as a whole, initiatives may have been most effective in stabilising or cutting down tobacco consumption among high educated men and women. In the country specific analyses, greater declines among men were mostly seen for those with less education. This contrasts with the pattern for women, where greater declines were more common among those with higher education.

\section{Study limitations}

A number of limitations need to be acknowledged before the findings are discussed in relation to the literature and implications of the study are stated. One limitation relates to the use of different sampling methodologies, interview procedures, and questions between countries. All surveys incorporated in this study relied on self reported smoking status, which may have led to some underestimation of smoking prevalence. Survey participation rates varied from

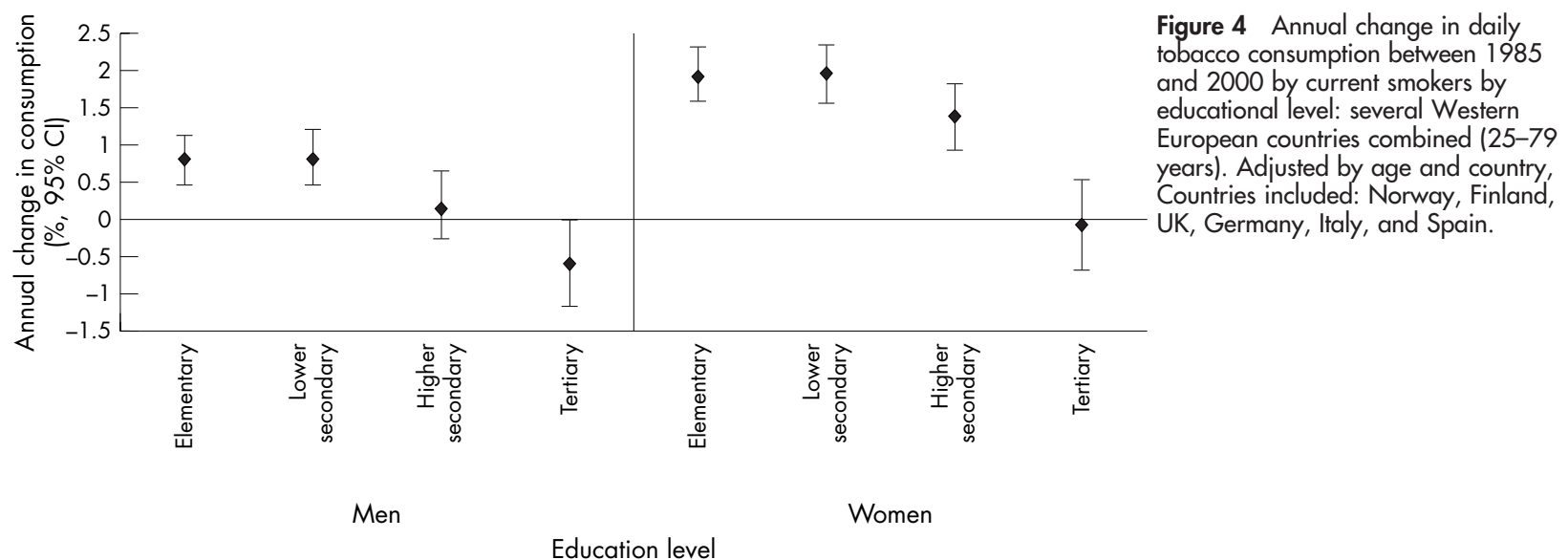




\section{Key points}

- The past two decades saw a rise in tobacco control policy aimed at discouraging smoking in Western Europe, however there has been no examination of the corresponding trends in smoking behaviour of different education groups in over this period.

- The findings show that there have been pronounced inequalities in smoking trends in a number of countries, with declines being less among low educated groups, showing that education inequalities in smoking related disease may increase in the future.

- The opposite trends were seen among British and Italian men, with greater declines noted among the least educated. This may be the consequence of the implementation of tobacco control policies that effectively reach and target the behaviour of low educated groups in these countries.

$56 \%$ to over $90 \%$. There was a large decline in response rate in the last UK survey, in which lower socioeconomic groups were less likely to participate, ${ }^{8}$ therefore these results should be interpreted cautiously. Furthermore, the combined country analyses included countries differing in their stage of the smoking epidemic. While the combined country analyses provide an indication of trends in the region, they may not reflect those of individual countries, particularly deviating countries (specifically, Italy and Spain).

\section{Findings of other research}

Previous studies have shown declining trends in smoking over the past two decades among men in northern, central, and southern European countries, ${ }^{9-15}$ and an overall stabilisation among women in most countries. ${ }^{10-14}$ Similar to this study, marginally larger declines in smoking have been seen among high educated Danish men compared with their less educated counterparts. ${ }^{11}{ }^{12}$ Previous research in Sweden has illustrated no obvious education differences in smoking trends among men, ${ }^{10}$ whereas our results suggest declines were greater among the high educated. Other studies in Italy have shown greater declines in smoking among high educated men compared with their less educated counterparts, ${ }^{13-15}$ whereas this study illustrated greater declines among the less educated. These discrepancies are presumably attributable to the greater number of time points and longer time period examined in this study, with the inclusion of data up until 2000. Declining inequalities in smoking have been reported among British men from the mid-1980s to the early $1990 \mathrm{~s}^{2}{ }^{2}$ which corresponds with the findings of this study. The findings among women correspond to those in the literature, which show net increases among low educated groups reported in Finland, ${ }^{9}$ Germany, ${ }^{16}$ Italy, ${ }^{13}{ }^{15}$ and increases found among disadvantaged women in Spain. ${ }^{17} 18$ Our study also illustrated the significant socioeconomic inequalities in current smoking trends, similar to other findings reported in the literature for Sweden, ${ }^{10}$ Denmark, ${ }^{11}{ }^{12}$ Germany, ${ }^{16}$ Italy, ${ }^{13}{ }^{15}$ and Spain, ${ }^{17}{ }^{18}$ with lower educated groups having the least favourable trends.

\section{Cigarette consumption}

A smaller body of literature has reported socioeconomic differences in population trends in the quantity of cigarettes that smokers consume. There is considerable cross sectional evidence in the literature that lower educated smokers consume larger quantities of cigarettes than their more educated counterparts. ${ }^{11} 15171920$ Among individual smokers, cohort studies show that tobacco consumption generally increases over time, a consequence of the addictive effects of nicotine. ${ }^{15}$ Among tertiary educated men, both prevalence and cigarette consumption declined, showing that among this group there was a net movement of smokers quitting and decreasing their cigarette consumption. Among elementary and lower secondary educated women, both prevalence and cigarette consumption increased simultaneously, suggesting there was an overall movement of women starting and becoming more addicted to smoking in these groups. Prevalence and cigarette consumption trends among women with higher secondary education showed that there was a large group of smokers becoming increasingly addicted. Among tertiary educated women, declining prevalence and stable cigarette consumption were seen. These trends show that among this education group, some smokers were becoming increasingly dependent, but this was offset with smokers decreasing their consumption or quitting, or both. Overall, the findings show higher educated groups may have a more active commitment toward quitting.

\section{The smoking epidemic model}

Trends in this study can be explained by the smoking epidemic model. ${ }^{17}$ Northern European countries are considered to be in stage 4 , characterised by reductions in smoking among men from all education groups, but greater reductions among those from lower education groups. Southern European countries are thought to be in stage 3, which is depicted by declines in smoking among men but increases among women, and central countries are considered to lie somewhere in between. ${ }^{3}$ Most findings of this study support this, however trends among the Finnish did not fit the northsouth pattern, as they were more typical of late stage 3 of the epidemic. If trends continue to follow this model, education inequalities in smoking may increase among women in Finland and in southern Europe over the next 5-10 years, before declines in smoking behaviour are seen among lower socioeconomic groups. The findings of this study also support the hypothesis that women are somewhat behind their progression through the smoking epidemic, evidenced by greater declines among more educated women in many of the countries compared with greater declines among less educated men in most countries. Despite country variations in the stage of the smoking epidemic, inequalities in smoking seem to constitute a problem whose roots are common to all European countries.

A noteworthy finding was that smoking decreased more rapidly among low educated British and Italian men compared with their more educated counterparts. It must be noted here that this finding from the UK should be interpreted cautiously, because of the large decrease in response rate between the third and fourth surveys and the participation bias under-representing low educated groups. An influential factor that decreases smoking, and that possibly contributed to the education differences in trends seen among British and Italian men is the price of cigarettes. A pricing policy was active throughout the study period in both countries and the price of cigarettes increased more rapidly in these countries in comparison with other countries. Other policies that have been shown to be particularly effective for decreasing smoking among low educated groups are bans/restrictions on advertising and promotion of tobacco products, smoking in indoor workplaces, telephone help lines, and free/subsidised access to smoking cessation therapies. ${ }^{21}$ In the UK other measures have also been implemented over the study period to assist low educated groups to quit smoking, such as free access to nicotine replacement patches, smoking clinics in disadvantaged 
neighbourhoods, and the provision of telephone quit lines, and these may have contributed to greater declines among the less educated. In Italy, bans/restrictions on the advertising and promotion of tobacco products and smoking in indoor workplaces were implemented and cessation clinics and telephone help lines were also introduced over the period studied, and these may have also contributed to the education differences in the trends seen.

\section{Conclusion/implications}

The results of this study show that smoking trends from the 1980s to the current time differed between education groups in the combined country and some country specific analyses. In combined country analyses, smoking declined least among low educated groups. One potential contributing factor to these findings is that tobacco control efforts and policies adopted over this period were not equally effective in changing the behaviour of different education groups, or that policies affected education groups differently. Efforts should be directed toward understanding whether tobacco control policy has similar effects by education group for men and women, and between countries. Additional knowledge is required to determine why quit attempts are less successful among low educated groups. Further research is justified to examine the effects of the price of cigarettes on the smoking behaviour of different education groups across a number of countries, and to investigate the tobacco control efforts in countries where greater declines among disadvantaged groups were evident.

\section{GUARANTOR}

The principal author, K Giskes, accepts responsibility for the conduct of the study, had access to the data, and controlled the decision to publish.

\section{Authors' affiliations}

K Giskes, A E Kunst, J A A Dalstra, B Federico, J P Mackenbach, Erasmus Medical Centre, Netherlands

J Benach, Universitat Pompeu Fabra, Spain

C Borrell, Agència de Salut Pública de Barcelona, Spain

G Costa, University of Turin, Italy

E Dahl, Norwegian Health Services Research Centre

U Helmert, University of Bremen, Germany

K Judge, University of Glasgow, Scotland

E Lahelma, University of Helsinki, Department of Public Health, Finland

K Moussa, P O Ostergren, University of Lund, Sweden

S Platt, University of Edinburgh, Scotland

R Prattala, National Public Health Institute, Finland

N K Rasmussen, National Institute for Public Health, Denmark

Funding: the research received financial support from the "Tackling Socioeconomic Inequalities in Smoking" project funded by European Commission. The funding body had no direct involvement in the study design; in the collection, analysis, and interpretation of data; in the writing of the report; and in the decision to submit the paper for publication.

Competing interests: none declared.

\section{REFERENCES}

1 Pierce J. International comparisons of trends in cigarette smoking prevalence. Am J Public Health 1989;79:152-7.

2 Bartley M, Fitzpatrick R, Firth D, et al. Social distribution of cardiovascular disease risk factors: change among men in England 1984-1993. J Epidemiol Community Health 2000;54:806-41.

3 Cavelaars A, Kunst A, Geurtts J, et al. Educational differences in smoking: international comparison. BMJ 2000;320:1102-7.

4 Irribaren C, Luepker R, MCGovern P, et al. Twelve-year trends in cardiovascular disease risk factors in the Minnesota heart study: are inequalities widening? Arch Intern Med 1997; 157:873-81.

5 Shafey O, Dolwick S, Guindon G. Tobacco control country profiles. Atlanta, GA: American Cancer Society Incorporated, 2003:1-437.

6 Dalstra J, Kunst A, Geurtts J, et al. Trends in socioeconomic health inequalities in the Netherlands, 1981-1999. J Epidemiol Community Health 2002;56:927-34

7 Kunst A, Looman C, Mackenbach J. Measuring the magnitude of socioeconomic inequalities in health: an overview of available measures illustrated with two examples from Europe. Soc Sci Med 1997;44:757-71.

8 Walker A, O'Brien M, Traynor J, et al. Living in Britain: results from the 2001 general household survey. Norwich: National Statistics Office, 2002:1-299.

9 Lahelma E, Rahkonen O, Berg M, et al. Changes in health status and health behaviour among Finnish adults 1978-1993. Scandinavian Journal of Work and Environmental Health 1997;23:85-90.

10 Peltonen M, Huhtasaari F, Stegmayr B, et al. Secular trends in social patternings of cardiovascular risk factor levels in Sweden. The Northern Sweden MONICA study 1986-1994. J Intern Med 1998;244:1-9.

11 Osler M, Prescott E, Gottschau A, et al. Trends of smoking prevalence in Danish adults, 1964-1994. The influence of gender, age and education. Scand J Soc Med 1998;26:293-8.

12 Osler M, Kirchoff M. Smoking behaviour in Danish adults from 1982 to 1992. Public Health 1995;109:245-50.

13 Cesana G, de Vito G, Ferrario $M$, et al. Trends of smoking habits in northern Italy. The WHO MONICA project in Area Brianza, Italy. Eur J Epidemiol 1995;11:251-8.

14 Ferrario M, Sega R, Chatenoud L, et al. Time trends of major coronary risk factors in a northern Italian population (1986-1994). How remarkable are socioeconomic differences in an industrialized low CHD incidence country? Int J Epidemiol 2001;30:285-91.

15 Faggiano $F$, Versino $E$, Lemma P. Decennial trends of social differentials in smoking habits in Italy. Cancer Causes Control 2001;12:665-71.

16 Mazaik W, Hense H, Doring A, et al. Ten-year trends in smoking behaviour among adults in southern Germany. International Journal of Tuberculosis and Lung Diseases 2002;6:824-30.

17 Graham H. Smoking prevalence among women in the European Community 1950-1990. Soc Sci Med 1996;43:243-54.

18 Shiaffino A, Fernandez E, Borrell C, et al. Gender and educational differences in smoking initiation rates in Spain from 1948 to 1992. Eur J Public Health 2003; 13:56-60.

19 Whitlock G, MacMahon S, van der Horn S, et al. Association of environmental tobacco smoke exposure with socioeconomic status in a population of 7725 New Zealanders. Tobacco Control 1998;7:276-80.

20 Rohrmann S, Becker N, Kroke A, et al. Trends in cigarette smoking in the German centers of the European prospective investigation into cancer and nutrition (EPIC): the influence of educational level. Prev Med 2003;36:448-54.

21 Kunst A, Giskes K, Mackenbach J. Socioeconomic inequalities in smoking in the European Union: applying an equity lens to tobacco-control policies. Brussels: European Network of Smoking Prevention, 2004:1-40. 